\title{
Meio ambiente e a educação ambiental na formação do pedagogo
}

\section{Theóffillo da Silva Lopes ${ }^{1}$ e Francisco José Pegado Abílio ${ }^{2}$}

${ }^{1}$ Universidade Federal da Paraíba. Centro de Educação. Programa de Pós-Graduação em Educação. Campus I. Cidade Universitária. João Pessoa-PB, Brasil (CEP 58051-900).E-mail: theoffillo@outlook.com.

${ }^{2}$ Universidade Federal da Paraíba. Centro de Educação. Departamento de Metodologia da Educação. Campus I. Cidade Universitária. João Pessoa-PB, Brasil (CEP 58051-900).

Resumo. 0 presente trabalho busca discutir a relação entre educação e meio ambiente, a formação do pedagogo e a importância da educação ambiental nesta formação. Para tanto se faz uma descrição e definição dos aspectos que envolvem essas relações, a exemplo da transdisciplinaridade, da transversalidade, do currículo, e do papel da universidade na construção do pensamento crítico dentro da formação de tais profissionais. Os conceitos de meio ambiente e de educação ambiental, assim como a mediação da educação e o meio ambiente através da interdisciplinaridade são evidenciados e discutidos. Nesse contexto da transversalidade ambiental na educação emerge a necessidade dos saberes ambientais inseridos na formação inicial de professores, ratificando a importância da educação ambiental na formação do pedagogo. Remetendo assim ao papel eminente da universidade na formação do pedagogo, na busca da superação de uma formação tecnicista para o mercado de trabalho, alcançando patamares de formação emancipatória e política, que visa a compreender dentro de uma perspectiva justa e equalitária. Observa-se assim a necessidade de incluir a Educação Ambiental nos cursos superiores de licenciatura, para que ela realmente exerça seu papel de forma transversal nas escolas, a partir da formação da nova geração de educadores que chega às instituições de ensino, reconhecendo a dimensão ambiental no âmbito das formações acadêmicas.

Palavras-chave: Educação; Educação ambiental; Formação do pedagogo; Meio ambiente.

\begin{abstract}
Environment and environmental education in pedagogue formation. This paper seeks to discuss the relationship between education and the environment, the education of the pedagogue and the importance of environmental education in this training. In order to do so, a description and definition of the aspects that involve these relationships is made, such as transdisciplinarity, transversality, curriculum, and the role of the university in the construction of critical thinking
\end{abstract}

Recebido

$06 / 06 / 2021$

Aceito

$09 / 07 / 2021$

Disponível on line

$11 / 07 / 2021$

Publicado

$31 / 08 / 2021$

Acesso aberto

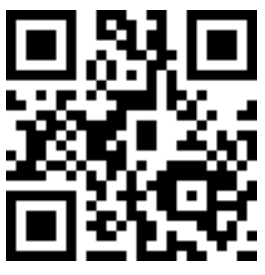

ORCID

(D) 0000-0002-7775-4885 Theóffillo da Silva

Lopes

(1) 0000-0002-7217-4849

Francisco José Pegado Abílio

Rev. Bras. Gest. Amb. Sustent.

http://revista.ecogestaobrasil.net 
within the training of such professionals. The concepts of environment and environmental education, as well as the mediation of education and the environment through interdisciplinarity are highlighted and discussed. In this context of environmental transversality in education emerges the need for environmental knowledge inserted in the initial teacher training, ratifying the importance of environmental education in the education of the pedagogue. Referring to the eminent role of the university in the education of the pedagogue, in the quest for overcoming a technical training for the labor market, reaching levels of emancipatory and political training, which seeks to understand within a fair and equalitarian perspective. Thus, it is necessary to include Environmental Education in higher education courses, so that it really plays its role transversally in schools, from the formation of the new generation of educators that reaches the educational institutions, recognizing the dimension environmental protection within the framework of academic training.

Keywords: Education; Environment; Environmental education; Formation of the pedagogue.

\section{Introdução}

Em meio às problemáticas emergentes do mundo pós-moderno a humanidade depara-se com grandes desafios que afligem o desenvolvimento das sociedades no mundo inteiro. A formação humana é atrelada intrinsecamente a sua relação com o ambiente em que vive. $O$ habitat humano traz em si um sistema conectado com as ações antrópicas, $o$ qual vem sofrendo consequências pelo modo irresponsável com que a humanidade tem-se comportado.

A problemática ambiental remete, portanto, a existência de uma urgente necessidade em obter uma nova postura sobre o contexto social e ambiental. Neste contexto, a Educação Ambiental apresenta-se como resposta à amenização dessa problemática, englobando-se num processo de apresentação de conceitos e adoção de valores, com respeito à diversidade, através de uma maior sensibilização, ou seja, da mudança de atitude em relação ao meio.

A priori é possível afirmar que o campo da Educação Ambiental ainda apresenta seus primeiros passos no campo educacional e também na formação e capacitação de professores para a mesma finalidade.

De acordo com ensaio aqui descrito compreende-se a necessidade de analisar a formação do pedagogo e sua relação com a Educação Ambiental e ainda o seu papel perante tal realidade.

Esta análise da formação do pedagogo e sua relação com a Educação Ambiental torna-se relevante devido a sua configuração no processo educativo, e serem fundamentados em valores de respeito e mudança de hábitos e costumes de postura egoísta e irresponsável. Esta análise ainda se evidência em caráter pertinente por apresentar uma maior reflexão sobre os desenvolvimentos científico, tecnológico e econômico e na equidade de acesso a condições de vida digna para as comunidades, uma vez que a Educação Ambiental configura-se em caráter holístico.

A Educação Ambiental atrelada à formação do pedagogo trata-se de um novo conceito de um educador que vai além do ser social, mas que traz em sua formação a 
necessidade de incorporar o adjetivo socioambiental, com o intuito de em que sejam retomados os princípios de conexão com a questão natural do ser humano objetivando uma melhoria das condições ambientais e a manutenção da vida no Planeta.

A inserção da grandeza da temática ambiental na educação vem sendo recomendada em inúmeros fatores que influenciaram as políticas públicas no Brasil.

No entanto, é perceptível um obstáculo. A Educação Ambiental não tem sido contemplada como uma abordagem interdisciplinar e transversal nos currículos dos cursos de formação de professores, nem mesmo naqueles que seguem as novas diretrizes para formação docente a partir de uma base comum filosófica, sociológica, política e psicológica, articulada com os conteúdos de formação específica.

Nessa perspectiva, é possível observar que a transformação da realidade ainda se apresenta com timidez uma vez que o desenvolvimento de atitudes, posturas e a ressignificação de valores, característicos da Educação Ambiental, encontram-se com um grande obstáculo e dificilmente conseguem inovar o processo da Educação de um modo geral pelo fato da ausência da inclusão da dimensão ambiental no currículo.

Desta forma, diferentes perspectivas têm sido utilizadas na formação inicial de professores em Educação Ambiental. Uma vez que, na formação docente, convêm questionar o ponto de vista dado ao processo de formação para a ampliação de conhecimentos, habilidades e competências, além de valores, princípios e ações necessárias para a inclusão da temática ambiental nos currículos como uma das dimensões do processo educacional.

O que se observa na Educação Ambiental é que as mudanças exigidas no processo de formação, no sentido da transformação de atitudes e valores, e, portanto, na prática pedagógica dos professores, parece incidir por meio de um trabalho a médio e longo prazo, ou seja, se o professore optar por obter essa formação ele tem que optar por uma especialização na área, sendo assim os que não optarem não terá essa formação tão necessária.

Identifica-se, portanto, a escola e a comunidade como protagonistas de mudanças ambientais. Nessa perspectiva, fica claro que é por meio da educação que é possível edificar uma sociedade justa e sustentável, além de buscar valorizar os aspectos culturais, éticos, ecológicos e sociais.

\section{O princípio da educação como alicerce para a formação do indivíduo}

No amparo das considerações que dizem respeito ao conceito de educação, tornase claro que não é possível fechar os olhos e acreditar que o processo educativo está presente apenas na escola, deve-se também acreditar em programa de intervenção pedagógica fora da escola, ou seja, a educação deve ser considerada sendo ela manifestada em toda e qualquer esfera social.

Portanto, a escola e a comunidade como protagonistas de mudanças ambientais. Nessa perspectiva, é primaz a compreensão de que por meio da educação que é possível edificar uma sociedade justa e sustentável, além de buscar valorizar os aspectos culturais, éticos, ecológicos e sociais.

$\mathrm{Na}$ esteira das discussões sobre as relações humanas e suas interferências no meio natural, destaca-se o processo educativo como alicerce da construção para uma sociedade em que os sujeitos tenham a competência de estabelecer comportamentos e ações que tragam benefícios para os indivíduos viverem em situação de equidade socioambiental. Tal realidade apresenta uma série de fatores que junto ao planejamento de qualquer modalidade de ensino pode ser transformado, basta obter um eixo norteador para que assuntos relativos à vida em sociedade possam ser discutidos dentro no âmbito educacional. 
No entendimento de um eixo norteador da educação de uma maneira abrangente é possível encontrar alguns termos usuais do cotidiano educacional atualmente, os quais seriam transdisciplinaridade, transversalidade e currículo.

0 termo transdisciplinaridade, em sua própria escrita, observa-se que o prefixo "trans" refere ao conhecimento que está além de qualquer disciplina tendo por intuito a interpretação do mundo diante a junção de vários aspectos relacionados entre si. 0 termo transdisciplinaridade foi utilizado pela primeira vez no I Seminário Internacional sobre pluri- e interdisciplinaridade, na Universidade de Nice, em 1970, pelo então renomado Piaget (1970), que estimulou uma maior reflexão sobre uma influência mútua entre as diversas disciplinas, sem que estas consumissem suas especificidades, assim implicaria, portanto, em uma colaboração para um saber comum, que se apresentasse da forma mais completa, e não apenas a uma única disciplina.

A decorrência de uma atitude de metodologia transdisciplinar apresenta-se como uma redução do jeito impresumível da individualidade e encerramento das disciplinas. Sendo assim a transdisciplinaridade apresenta-se como uma visão harmônica com a atualidade, na qual a pluralidade e a contestação fazem presentes. Sendo assim, é viável compreender a transdisciplinaridade como uma nova postura e não como o império sobre as outras disciplinas e sim uma abertura de todas estas.

Assmann (1998) destaca dois elementos básicos do conceito de transdisciplinaridade,

primeiro, trata-se de algo mais que a mera intensificação do necessário diálogo entre as distintas áreas e disciplinas científicas, porque a questão que precisa ser explicitada é a da mudança de paradigma epistemológico; segundo, o diálogo entre as ciências será mais profundo se houver uma transmigração de conceitos fundamentais através das diversas disciplinas.

De acordo ainda com Japiassu (1992), são condições para a ocorrência do transdisciplinar:

a) que o homem inteligente oponha à cegueira do especialista a compreensão de situações complexas;

b) que recuse todo o caráter territorial do poder pelo saber;

c) que abandone a concepção de uma verdade que seria assimilada à busca causal da coisa. Japiassu (1992)

Em suma, a transdisciplinaridade surge da constante reivindicação de aplicar o diálogo entre diversos palcos do saber sem fixar o domínio de uns sobre os outros, garantindo um modo e uma atitude que norteiem a influência mútua entre os profissionais e seus conhecimentos. Recomendada pelos PCN's a transdisciplinaridade trazem em sua essência uma lógica articuladora de conhecimentos de diversas disciplinas, objetivando ultrapassar as fronteiras de cada campo do saber.

0 conceito de transversalidade apareceu na conjuntura dos movimentos de renovação pedagógica, quando os teóricos idealizaram que seria indispensável redefinir o que se entende por aprendizagem e repensar os conteúdos que se ensinam aos alunos. $\mathrm{Na}$ esfera da contribuição dos PCNs, a transversalidade tem por intuito possibilitar na prática educativa, uma relação entre aprender conhecimentos teoricamente sistematizados, ou seja, aprender sobre o cotidiano e os assuntos da vida real além de sua transformação aprender na realidade e da realidade. Busca-se uma mova maneira de apresentar para os conteúdos e para a metodologia da área o ponto de vista das temáticas. E sendo assim, os PCNs sugerem os temas transversais que satisfazem a questões importantes, pertinentes, urgentes e presentes sob várias óticas de ver a vida cotidiana como por exemplo ética, saúde, meio ambiente, orientação sexual, trabalho e consumo e pluralidade cultural. 
De acordo com Guattari (2004):

A transversalidade é uma dimensão que pretende superar os dois impasses, quais sejam o de uma verticalidade pura e de uma simples horizontalidade; a transversalidade tende a se realizar quando ocorre uma comunicação máxima entre os diferentes níveis e, sobretudo, nos diferentes sentidos (Guattari, 2004, p. 111).

A transversalidade surge atualmente como princípio inovador dos aparelhos de ensino de diversos países. Mas essa nova concepção não novidade recente, pois a mesma ressurge dos ideais pedagógicos do início do século.

Partindo desta afirmação, fica claro constatar a transversalidade como uma abertura para um novo patamar teórico o qual transcorrem de inúmeras decorrências práticas, seja no campo das metodologias de ensino tanto quanto em uma nova proposta curricular e pedagógica.

Em contexto com a transdisciplinaridade e a transversalidade encontra-se ainda outro termo pertinente a essa discussão: o currículo. Ao pé da letra, ou melhor dizendo, segundo a etimologia da palavra currículo, seu significado apresenta múltiplos sentidos como por exemplo: ato de correr, atalho, pista de corrida. Portanto, a definição de currículo vai muito além do que sua etimologia passa, pois sua definição não se apresenta como uma tarefa fácil, sobretudo para os profissionais da educação, uma vez que esse termo tenha sofrido várias influências e ainda tenha sido adequado, de maneiras diversas, e na maioria das vezes contrárias as suas reais especificidades. 0 currículo traz consigo a cultura, a crença, a forma de governo de um determinado lugar e isso têm levado a lutas inflexíveis que envolvem os princípios da educação. O currículo, segundo Silva (2005), sempre foi construído para determinar efeitos sobre as pessoas.

\begin{abstract}
Nessa perspectiva, o currículo deve ser visto não apenas como a expressão ou a representação ou o reflexo de interesses sociais determinados, mas também como produzindo identidades e subjetividades sociais determinadas. 0 currículo não apenas representa, ele faz. É preciso reconhecer que a inclusão ou a exclusão no currículo tem conexões com a inclusão ou exclusão na sociedade (Silva, 2005, p. 10).
\end{abstract}

Considerando a conceituação acima, é notória a importância do currículo para um determinado modelo de educação que se almeja alcançar, sempre na compreensão de que o currículo não se apresenta de forma neutra, pois ele traz em suas raízes resquícios e nuances dos interesses de uma determinada sociedade.

\title{
O conceito de meio ambiente e sua relação com a educação
}

Em 1970, a poluição torna-se presente em níveis mundiais e o alerta para a preservação ambiental torna-se evidente, surgindo assim uma real necessidade de preparar as futuras gerações para o conhecimento acerca do meio ambiente.

A crise pela qual a humanidade atravessa tem como cenário o contexto ambiental, ou seja, o meio ambiente propriamente dito. Em termos mais substanciais, a legislação brasileira, mais especificamente a Política Nacional do Meio Ambiente, em seu art. 3을 inciso I, da Lei no 6.938/1981 (Brasil, 1981), conceitua meio ambiente como o "conjunto de condições, leis influências e interações de ordem física, química e biológica que permite, abriga e rege a vida em todas as suas formas".

A conceituação do termo data de época recente na sociedade brasileira. Leff (2001) aponta que tal preocupação só surgiu diante sérios agravantes ambientais a exemplo da chuva ácida, mudanças climáticas, poluição e tantos outros fatores. 
Em Grispun (2008) é ressaltado que estender o significado de meio ambiente natural ao significado de meio ambiente social, ampliando-se cuidados com o meio ambiente e ao meio social, contemplando valores de vida cidadã, que incluem saúde, sexualidade, família, trabalho, ciência e tecnologia, cultura, linguagens, etc.

Essa conceituação sobre meio ambiente nem sempre é compreendida de forma plausível e contemplada no currículo de maneira satisfatória, pois o ser humano ainda na maioria das vezes vê-se dissociado do seu meio natural. Essa relação não é muito distante do que ocorre com o âmbito educacional, o currículo voltado a Educação Ambiental e seus reais princípios ainda vem sendo construídos ao longo do processo educacional.

Portanto, ao se tratar de Educação Ambiental e formação de professores é primaz compreender qual o significado do termo chave para àqueles que venham a contribuir para a melhoria da formação humana necessária a sociedade global atualmente.

A importância da inserção do conceito sobre meio ambiente torna-se relevante no Brasil na década de 1960, com isso mais adiante surge uma maior preocupação em se relacionar a educação com a vida do aluno, ou seja, uma aprendizagem condizente com o cotidiano do educando.

Para Campos (2006), a relação entre meio ambiente e sustentabilidade passa pela educação, em todos os níveis. Concomitante a isso, Campos (2006) aborda ainda outras metas para o alcance de uma sustentabilidade que estão inteiramente ligadas às questões sociais, o que deixa em evidência o caráter social dos problemas ambientais. Entre essas metas estão a satisfação das necessidades básicas da população, a solidariedade com as gerações futuras, a participação da população na linha da Agenda 21, a conservação dos recursos vitais, em como um sistema social justo.

Com isso, evidencia-se o papel socioambiental de um processo educativo definido e objetivado. Segundo Stone e Barlow (2006), reorientar o modo como os seres humanos vivem e educá-los para que atinjam seus potenciais mais elevados são tarefas com aspectos bem semelhantes, ambas têm de ser vistas e abordadas no contexto dos sistemas familiar, geográfico, ecológico e político.

Afinal, como afirma Lima (2008), “[...] pergunta-se e problematiza-se, crescentemente, qual a contribuição do processo educativo na busca de respostas aos múltiplos e, cada vez mais, frequentes problemas socioambientais" (Lima, 2008, p. 109).

Considerando que a educação é um processo de aprendizagem permanente, essa mesma, quando se volta para a sustentabilidade deve respeitar todas as formas de vida, deve considerar valores e ações que contribuam não só para a conservação ecológica, como também para a transformação humana e social. Tal educação estimula a formação de sociedades críticas, justas e ecologicamente equilibradas. Lima (2003) considera que o discurso da sustentabilidade traz implicações para a Educação, implicações essas que vão surgir como contrapartida ao modelo hegemônico capitalista de desenvolvimento, por isso, faz-se necessário assim uma Educação que, vem contribuir em um processo interativo, participativo e crítico para o surgimento de uma nova ética, está vinculada e condicionada a mudanças de valores, atitudes e práticas individuais.

Portanto, ao se tratar de Educação Ambiental e formação de professores, é importante compreender qual o significado do termo chave para aqueles que venham a contribuir para a melhoria da formação humana necessária à sociedade global atualmente.

Quando se fala em relação entre meio ambiente e educação, não se podem deixar de lado alguns conceitos que estão atrelados a essa relação. Conceitos como o de transdisciplinaridade, a transversalidade, e o ponto de encontro entre estes, o currículo. 


\section{0 conceito de educação ambiental}

Para melhor compreender o que é a Educação Ambiental, o art. 1ํㅡ, da Lei $\mathrm{n}^{0}$ 9.795/1999, explicita:

Processo em que se busca despertar a preocupação individual e coletiva para a questão ambiental, garantindo o acesso à informação em linguagem adequada, contribuindo para o desenvolvimento de uma consciência crítica e estimulando o enfrentamento das questões ambientais e sociais. Desenvolve-se num contexto de complexidade, procurando trabalhar não apenas a mudança cultural, mas também a transformação social, assumindo a crise ambiental como uma questão ética e política (Brasil 1999).

Ao analisar a lei, é notória que a mesma traça as diretrizes e os princípios elementares da educação ambiental, como também fornecem seus objetivos fundamentais, os quais seriam um desenvolvimento de uma compreensão associada do meio ambiente, em suas múltiplas e complexas relações, envolvendo aspectos ecológicos, legais, políticos, sociais, econômicos, científicos, éticos e culturais; o fortalecimento de uma consciência crítica sobre a problemática ambiental e social; o incentivo à participação individual e coletiva, permanente e responsável, na conservação do equilíbrio do meio ambiente, compreendendo a defesa da qualidade ambiental como um valor intrínseco do pleno exercício da cidadania.

A educação implica não só na conscientização e no olhar crítico da realidade, mas visa ao desenvolvimento da cidadania. Neste aspecto, apenas ela comporta ao educando uma construção de valores sociais e o desenvolvimento pleno de suas habilidades e de sua visão crítica do mundo. No caso do meio ambiente, é de extrema valia conscientizar a população que a natureza é fator primordial da nossa existência e a sobrevivência de novas gerações. Ou ainda como afirma Guimarães (1995) obter a participação de todos os atores, educandos e educadores, na construção de um novo paradigma que contemple as aspirações populares de melhor qualidade de vida socioeconômica e um mundo ambientalmente sadio.

A Educação Ambiental deve ocorrer de maneira relacionada com a ação do homem e suas causas, pode-se compreendê-la ainda como uma mudança de valores no âmbito social. De acordo com a conceituação de Educação Ambiental em Branco (2003), essa seria um conjunto de iniciativas educacionais de todos os setores da sociedade, na busca de uma consciência ambiental.

Em relação à prática da Educação Ambiental, Maturana (1998) afirma que essa deva ser:

Uma educação que promova: atuação na conservação da natureza e compreensão a ponto de excluir a ideia de domínio; convívio com responsabilidade pelo individual e pelo coletivo; distanciamento de qualquer abuso (Maturana, 1998, p. 170).

Isso implica que a Educação deve tratar educando e educador como agentes transformadores da sociedade, que se abrangem entre si, para os problemas socioambientais da comunidade, como afirma Guimarães (2000).

Em ambos os autores é possível identificar que a prática da educação ambiental pode levar o indivíduo a conservar o meio ambiente em que vive, uma vez que aquela mostra que o ser humano é um ser capaz de transformar a própria realidade social. 
A definição da Educação Ambiental traz em sua essência os processos permanentes de aprendizagem e formação individual e coletiva para reflexão e construção de valores, saberes, conhecimentos, habilidades, atitudes e competências, visando à melhoria da qualidade de vida e a uma relação sustentável da sociedade humana com o ambiente que integra. Em suas palavras, Guimarães propõe:

\begin{abstract}
Em função de tudo isso, a EA [educação ambiental] tem o importante papel de fomentar a percepção da necessária integração do ser humano com o meio ambiente. Uma relação harmoniosa, consciente do equilíbrio dinâmico na natureza, possibilitando, por meio de novos conhecimentos, valores e atitudes, a inserção do educando e do educador como cidadãos no processo de transformação do atual quadro ambiental do nosso planeta (Guimarães, 1995, p. 15).
\end{abstract}

De acordo com Leff (2001), a Educação Ambiental traz uma nova pedagogia que precisamente orienta a educação; que implica práticas concretas que se desenvolvem no meio, que induz transformações do conhecimento a partir de uma nova percepção das relações entre processos ecológicos, econômicos, sociais; que implica tornar o ambiente em seu contexto físico, biológico, cultural e social como uma fonte de aprendizagem; que leva a internalizar os princípios e valores ambientais nos conteúdos, enfoque e práticas dos processos educativos.

A Educação Ambiental deve enfocar tanto a conscientização e transmissão de conhecimentos, quanto à promoção de valores e hábitos, o desenvolvimento de habilidades, a orientação para a tomada de decisões, e a busca para a solução dos problemas ambientais, como afirma Pedrini (2006).

A Educação Ambiental desponta assim como um processo educativo idêntico à educação formal, só que dando uma dimensão ambiental contextualizada e adaptada à realidade interdisciplinar, vinculada aos temas ambientais locais e globais. Assim, essa questão interdisciplinar traz para a relação meio ambiente, sociedade e sustentabilidade mais um pressuposto educacional, colocando em evidência a necessidade de uma educação ética, direcionada, política e emancipatória.

\title{
A formação do pedagogo e a educação ambiental
}

É no cenário grego que nasce os primeiros indícios da Pedagogia, através de Platão, considerado o primeiro pedagogo por acreditar na formação de indivíduos sábios, instigando sempre a inquietação do saber e valorizando a formação humana. Percebe-se então, o quão antigo é o pensamento educacional e o quanto a Pedagogia ganhou em inúmeras contribuições até os dias atuais. Novos conceitos foram incorporados às maneiras de ensino. As formas para se atingir as faculdades humanas, são estudadas até os dias atuais.

Em um contexto mais político e social Freire (2005) defende uma pedagogia libertadora que associa o processo de ensino às relações do educando com o mundo, com o seu contexto cultural, para que o indivíduo perceba-se como parte do processo de mudança, tanto da sua realidade como da realidade da sociedade, uma vez que todos estão inseridos no contexto de uma determinada cultura.

A Pedagogia começou a desenvolver-se no século XIX e apresenta-se, segundo Libâneo (1998), como a ciência que tem a prática social da educação como seu objeto de investigação e de exercício profissional, ou seja, que tem como objetivo investigar o processo educativo que pode estar presente, desde que seja intencionado, em todo lugar, seja em casa, na escola, numa organização, na empresa, dentro de outros ambientes. 
Ainda de acordo com Libâneo (1998), a formação do pedagogo no Brasil teve seu início por volta de 1939, quando foi regulamentada a primeira turma do curso de Pedagogia. Tal formação previa o título de bacharel em Pedagogia, naquela época conhecido como "técnico em educação/assuntos educacionais".

Com isso as leis vieram para amparar esse profissional. Até os tempos de hoje, desde a época da criação do curso, foram outorgadas três versões da Lei das Diretrizes e Bases da Educação Nacional. Em 1961, quando surgiu a Lei no 4.024/1961 (Brasil, 1961), que possibilitava o acesso ao nível superior para os egressos do atual ensino médio, em 1971, quando surgiu a Lei no 5.692/1971 (Brasil, 1971), com a função de atualizar a normalização antiga, e em 1996, foi sancionada a Lei no 9.394/1996 (Brasil, 1996), que buscou modificar o sistema educacional brasileiro, a fim de regulamentar a profissão tanto na esfera de formação de professores, quanto em gestão escolar e nas áreas de currículo.

Ainda no art. 62, da Lei das Diretrizes e Bases da Educação Nacional, pontua:

\begin{abstract}
A formação de docentes para atuar na educação básica far-se-á em nível superior, em curso de licenciatura, de graduação plena, em universidades e institutos superiores de educação, admitida, como formação mínima para o exercício do magistério na educação infantil e nas quatro primeiras séries do ensino fundamental, a oferecida em médio, na modalidade normal (Brasil, 1996).
\end{abstract}

Este artigo da Lei das Diretrizes e Bases da Educação Nacional evidencia de forma clara e coerente, quais são os quesitos fundamentais para se atuar na educação básica, coibindo qualquer prática pedagógica seja ela como professor ou pedagogo para quem não tem formação superior em Pedagogia.

Além da Lei das Diretrizes e Bases da Educação Nacional, em 15 de maio de 2006, o Conselho Nacional de Educação, do Conselho Pleno, outorgou a Resolução MEC/CNE/CP no 1/2006 (Brasil, 2006), que institui Diretrizes Curriculares Nacionais (DCN) para o Curso de Graduação em Pedagogia, definindo princípios e condições de ensino e aprendizagem, procedimentos a serem observados em seu planejamento e avaliação, pelos órgãos dos sistemas de ensino e pelas instituições de educação superior do país.

Nesse sentido, é possível compreender de forma geral a Pedagogia como a ciência do ensino, ou seja, da educação tanto no seu nível teórico, como prático, tendo também como prerrogativa, a melhoria do processo de aprendizagem dos indivíduos, através da prática reflexiva, da sistematização e produção de conhecimento. E entender ainda por pedagogo segundo Libâneo (1998):

Entendo, portanto, que a formação desse pedagogo para desempenhar atividades de pesquisa educacional, esse pedagogo que poderá atuar na direção de escola, coordenação, planejamento e avaliação educacional, informática educativa, comunicação e produção de mídias, materiais didáticos, gestão de educação especial, pedagogia empresarial, animação cultural, psicopedagogia, etc., quer dizer, isso caracteriza o pedagogo stricto sensu, o especialista deve ser formado num curso específico, tendo no final as habilitações (Libâneo, 1998, p. 53).

Desta forma de acordo com sua formação, o pedagogo, pode atuar desde professor das séries iniciais, do Ensino Fundamental I, tendo sua habilitação, como também pode orientar, fomentar, pesquisar, coordenar, planejar, ensinar, gerir, ações, metodologias voltadas para a temática ambiental. Uma vez que estando este profissional inserido no contexto cultural atual, seja ele trabalhando na escola, na empresa, ou em outra instituição, não deixa de deparar-se com a problemática ambiental, característica das sociedades atuais em qualquer que seja a área. 
A Pedagogia apresenta-se ainda como ciência social conectada com diversos aspectos da sociedade e com as normas educativas do país, cuja finalidade seria solucionar por meio de estudos e práticas pedagógicas, os problemas relacionados ao processo de ensino aprendizagem.

Em outros termos, tratando-se do aspecto do graduando em Pedagogia, o art. 3o, da Resolução MEC/CNE/CP no 1/2006, diz que:

0 estudante de Pedagogia trabalhará com um repertório de informações e habilidades composto por pluralidade de conhecimentos teóricos e práticos, cuja consolidação será proporcionada no exercício da profissão, fundamentando-se em princípios de interdisciplinaridade, contextualização, democratização, pertinência e relevância social, ética e sensibilidade afetiva e estética (Brasil, 2006).

0 trecho acima discorre claramente sobre os aspectos que competem ao estudante de Pedagogia, deixando clara a necessidade da pluralidade de conhecimentos, e para, além disso, fundamentar-se em princípios interdisciplinares e de relevância social.

0 profissional em Pedagogia é habilitado em atender a demanda socioeducativa de caráter formal, não formal e informal, podendo assim atuar em escolas, em movimentos sociais, em empresas, em educação de jovens e adultos, em serviços de psicopedagogia, em organizações não governamentais, projetos, dentre outras funções.

Segundo Libâneo (1998), o estudante de Pedagogia conhece o lado científico e filosófico da educação, e adquire conhecimentos teóricos e práticos de sua atuação, assim, em correspondência, o curso é dividido em três áreas: Conhecimentos científicos e filosóficos da educação; Conhecimentos específicos da atividade; e Conhecimentos técnicoprofissionais.

Relacionado às reais funções nas quais deve estar apto o graduado em Pedagogia, 0 art. 5o, da Resolução MEC/CNE/CP nº 1/2006, dispõe:

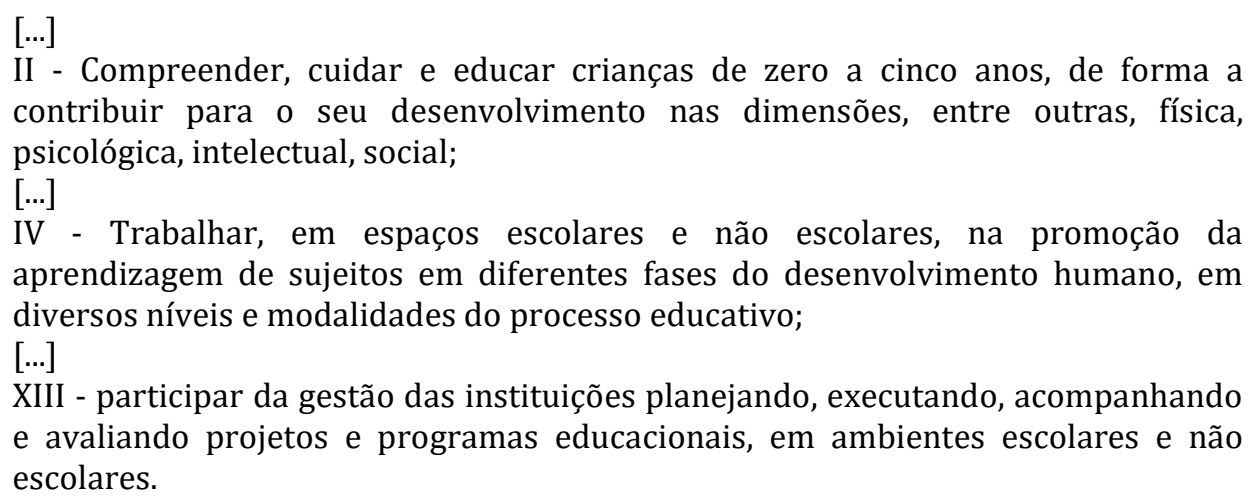

Esses aspectos da formação do pedagogo já revelam um perfil de um profissional, que tem em sua essência, características solícitas a uma real e intencionada educação, que se quer inserida e contextualizada com a dimensão ambiental e com as necessidades sócio ambientais na qual está inserida.

\title{
A importância da educação ambiental na formação do pedagogo
}

\begin{abstract}
A intenção de qualificar para diferenciar as propostas de Educação Ambiental presentes na sociedade é a de desvelar a apropriação ideológica que delas fazem grupos dominantes. Isto para que se possa contrapô-las, de fato, com a realização de práticas de Educação Ambiental, em que a ação crítica sobre o processo social possibilite a formação de cidadãos comprometidos com a questão da qualidade ambiental (Guimarães, 2000, p. 67).
\end{abstract}


Layrargues (2006), afirma que a Educação Ambiental antes de tudo, é Educação, e que esse é um pressuposto inquestionável. Partindo desse pressuposto e da necessidade de qualificar para diferenciar as propostas de Educação Ambiental, surge então, a figura do educador ambiental. Para Carvalho (2002), este sobrepõe no bojo de um movimento histórico que tem evidenciado a questão ambiental como um campo de ação político-pedagógica.

Essa perspectiva de ação pedagógica e de reflexão sobre a práxis é uma atividade que concebe a educação como crítica, que se faz solícita de desenvolvimento autônomo e emancipatório de todos quantos envolvidos no seu processo (Sato e Zakrzevski, 2001).

Acerca dessa emblemática da formação docente, afirma Perrenoud (2002), '0 ofício do professor só pode ter acesso ao paradigma reflexivo se seguir o mesmo itinerário crítico, já que nunca passou, em larga escala, pelo fantasma de uma prática "científica"' (Perrenoud, 2002, p. 15). Pode-se desta forma, compreender a dificuldade dos inúmeros profissionais que são lançados na prática profissional no decorrer de cada período. Perrenoud continua a enfatizar que a prática reflexiva é complexa e ao mesmo tempo trata-se:

\footnotetext{
- De ampliar as bases científicas da prática, onde elas existam, e lutar contra a ignorância ainda muito ampla das ciências humanas, da psicologia e, acima de tudo, das ciências sociais;

- De não as mistificar e de desenvolver formações que articulem racionalidade científica e prática reflexiva, não como irmãs inimigas, mas como duas faces da mesma moeda (Perrenoud, 2002, p. 16).
}

Dentro desse contexto é possível compreender que a ausência de uma prática reflexiva sobre a formação docente traz em suas raízes resquícios de uma formação acadêmica aquém da realidade vivenciada na sociedade de modo geral.

É consenso atualmente que os diversos saberes não são suficientes para enfrentar o mundo complexo e a heterogeneidade das situações no cotidiano profissional. É necessário, portanto, refletir sobre as novas formas de exercício de tal profissão. Com essa real situação, é solícita a formação de um profissional reflexivo da sua prática, que extraia o conhecimento através da experiência imposta a ele todos os dias, ou seja, a reflexão na ação e sobre a ação.

Neste sentido, Freire (1996) afirma que a prática docente crítica, implicante do pensar certo, envolve o movimento dinâmico, dialético, entre o fazer e o pensar sobre o fazer. Portanto, é solícito compreender a importância da prática reflexiva atrelada à prática docente.

Ainda sobre esses saberes necessários para compreender a complexidade do mundo, Morin (2001) apresenta sete saberes indispensáveis à educação do futuro. Dos quais cita introduzir e desenvolver na educação o estudo das características mentais, culturais, psíquicas e de conhecimentos humanos; desenvolver a aptidão natural para situar todas as informações em um contexto; evidenciar o elo indissolúvel entre a unidade e a diversidade de tudo que é humano; conhecer o destino planetário do gênero humano; ensinar princípios de estratégia que permitam enfrentar imprevistos; evidenciar a compreensão como tempo, meio e fim da comunicação humana; e contribuir não somente para a tomada de consciência da Terra-Pátria, como também permitir que essa consciência seja traduzida em vontade de realizar a cidadania terrena.

Morin (2001) evidencia, assim, uma relação intrínseca e íntima entre a educação e a consciência de que ela traduz em reconhecimento do papel nos efeitos da Terra. Dentre tais saberes é notória uma relação com a temática ambiental através de termos como a identidade e cidadania terrena, destino planetário. Com isso não tem como não afirmar 
que uma educação do futuro não permeie a dimensão ambiental na formação dos indivíduos.

Esses saberes, essa prática reflexiva, a compreensão da dimensão ambiental inserida diretamente na educação, não pode estar distanciada da formação dos professores, que por sua vez, serão os educadores que formarão agentes multiplicadores dessa consciência planetária.

Assim, a visão de um bom educador ambiental ancora-se no processo de formação desse profissional. Que, ao contrário de monitores e militantes ambientais, carece de autonomia, e independência crítica, política enquanto educação, formada, formando-se e formadora enquanto próprio educador (Cascino, 1999).

Esse processo, essa autonomia e independência, não se fazem diferentes para pedagogos, enquanto educadores e professores que também o são. Em trabalhos anteriores pode-se observar a constatação da necessidade da Educação Ambiental na formação de educadores (Rosa, 2003), ou que dentro das estratégias de Educação Ambiental, está a sensibilização e a formação dos educadores, que por sua vez transmitirão aos educandos (Silva, 2000).

Pode-se observar ainda em outros trabalhos uma percepção sobre a necessidade de vários aspectos que estão intrinsecamente ligados ao contexto escolar, onde se sobrepõe a prática pedagógica e a profissionalização dos educadores, para uma boa Educação Ambiental (Pequeno, 2001).

Fica clara, a importância de uma boa formação dos profissionais, como agentes capazes de intervir de maneira eficaz e consciente sobre a dimensão ambiental inserida na educação. Para isto, não se pode esquecer o meio ao qual tudo acontece, a universidade, onde se forma e se é formado.

Segundo Santos (2005), o conhecimento universitário deve apresentar-se de maneira transdisciplinar que, pela sua própria contextualização, obriga a um diálogo, ou confronto com os diversos tipos de conhecimentos.

Retornando a base desse estudo, depreende-se que a formação do pedagogo possui uma relação intrínseca com todo processo de conhecimento universitário e uma prática reflexiva.

O que se pode constatar no âmbito da inclusão da Educação Ambiental é que seria necessário refletir sobre o papel da universidade como instituição, aonde deverá produzirse uma inclusão da dimensão ambiental no currículo, o que vem a envolver as práticas de diversos agentes sociais: tanto professores, quanto alunos, comunidade, etc. Também é pertinente analisar os princípios filosóficos e epistemológicos que baseiam essas propostas.

A concepção de que a dimensão ambiental na educação só pode ser compreendida e trabalhada interdisciplinarmente é quase um consenso, mas ainda é pouco vivenciada na prática educativa.

Em Morin (2001), a complexidade é um termo que quer dizer uma trama de elementos que se juntam e forma um todo. Pode-se transpor esse conceito para a educação, e compreender que tudo deve estar inserido: o sujeito, o contexto, a história, a consciência e etc.

Dentro do entendimento desse imenso sistema de complexidade, nota-se que a Educação Ambiental também faz parte deste, e deve ser contemplada nos mais variados campos de formação profissional da sociedade, como é ratificado no art. $3^{3}$, inciso I, da Política Nacional de Educação Ambiental, que determina "promover a Educação Ambiental em todos os níveis de ensino e o engajamento da sociedade na conservação, recuperação e melhoria do meio ambiente" (Brasil, 1999).

A formação profissional dos diversos setores da sociedade traz em seu escopo, a difícil tarefa de tornar-se coerente com a prática exercida, e de ser pertinente ao mundo 
pós-moderno. A formação do pedagogo não se exclui desse universo, e faz-se solícita a um contexto educacional necessário à sociedade, de um modo geral e significativo.

Assim, a educação ambiental na formação do pedagogo deve apresentar-se como um processo educativo permanente, contínuo, global, socializante e gerador das transformações internas do homem em suas multifacetadas inter-relações com o meio.

Os Parâmetros Curriculares Nacionais (Brasil, 1997) abordam a educação ambiental como tema transversal e de papel indispensável para a transformação da consciência ambiental. Para tal, faz-se necessário uma mudança de mentalidade, conscientizando para a necessidade de adoção de novos hábitos.

Assim, é preciso que seja concebida, uma educação compromissada com a temática ambiental, que privilegie não apenas à espécie humana, mas o planeta como um todo; compreendendo que o homem somente existe se o próprio planeta existir. Neste aspecto, só existirão condições plenas de vida para o presente e o futuro se cada indivíduo possuir uma responsabilidade humana, social e ambiental.

À luz dessas reflexões, a universidade deve mostrar-se atenta, uma vez que o indivíduo não somente seja dotado de conhecimento técnico para exercício de uma profissão, mas para, além disso, obter formação suficiente para um caráter socioambiental justo e de equidade. Desta forma, é essencial considerar os cursos de graduação um espaço para esse novo pensar da ação educativa, assim como também dos próprios conteúdos curriculares.

De acordo com Sorrentino (1997), existe uma indelével importância da universidade enquanto mediadora na formação de profissionais e cidadãos, para atuarem dentro de uma proposta de melhoria da qualidade de vida, e de proteção e melhoria das condições ambientais, capazes de estimular processos educacionais voltados à questão ambiental, em todos os graus de ensino e aprendizagem.

Nota-se também em Silveira (1997) que há várias razões para enfatizar o papel da universidade no desenvolvimento da Educação Ambiental, ratificando dentre eles, o fato de a mesma acumular as funções de ensino, pesquisa, extensão e consultoria; por ser a universidade um fórum de diálogo, com a escola e a sociedade em geral; por ser um centro de pesquisa e, portanto, compreender a ciência como fator tanto de progresso e qualidade de vida, quanto de catástrofe; e por já aceitar a inter e transdisciplinaridade como alternativas curriculares.

Tratando-se do curso de graduação em Pedagogia, enquanto formador de professores da educação básica, este, não deve apresentar-se de forma omissa e distante do novo paradigma educacional.

Sabe-se que inserir a dimensão ambiental nas práticas pedagógicas, perpassa por uma pressão social e institucional, justamente por que elas encontram-se sendo formadas em grande maioria, a partir de um ponto de vista conservador e clássico de um sistema de educação, ou seja, "baseadas em uma compreensão de mundo adaptada pela racionalidade hegemônica, às quais geram práticas incapazes de fazer diferente do 'caminho único' prescrito por essa racionalidade, efetivando-se a hegemonia” (Guimarães, 2004, p. 124).

\section{Conclusões}

No Brasil, inúmeros pesquisadores, em suas áreas de atuação, estão incomodados com o procedimento e a discussão da formação em educação ambiental ou de educadores/as ambientais.

Nota-se que é eminente, a necessidade de incluir a Educação Ambiental nos cursos superiores de licenciatura, para que ela realmente exerça seu papel de forma transversal nas escolas, a partir da formação da nova geração de educadores que chega às instituições de ensino. 
Portanto, é preciso reconhecer a dimensão ambiental no âmbito de formações acadêmicas, para que se venha priorizar a adoção do meio ambiente local, para promover a atuação da comunidade na identificação dos problemas, e de suas soluções.

Com tudo, a ação educativa relativa a uma educação ambiental, sente-se a necessidade de obter uma formação de professores comprometida com a capacidade de exercer a cidadania de forma responsável, para que seja criada e ampliada a participação nas tomadas de decisões responsáveis, no que diz respeito ao âmbito socioambiental.

O respaldo na Constituição de 1988 (Brasil, 1988) já se faz presente inerente à Educação Ambiental, basta apenas um maior comprometimento e consideração voltados à ação educativa dos professores, de forma a satisfazer melhor as necessidades do atual sistema social que encontramos.

Em especial, o Curso de Pedagogia analisado nesse estudo encontra-se num patamar distinto, uma vez que forma os futuros profissionais da Educação. Neste sentido, almeja-se estabelecer uma cultura com caráter formador que forneça ao pedagogo, suporte para a compreensão desta tão pertinente área.

\section{Conflito de interesses}

Os autores declaram não haver conflito de interesses.

\section{Referências}

Assmann, H. Reencantar a educação: rumo à sociedade aprendente. 2. ed. Petrópolis: Vozes, 1998.

Branco, S. Educação ambiental: metodologias e prática de ensino. Rio de Janeiro: Dunya, 2003.

Brasil. Constituição da República Federativa do Brasil de 1988. Disponível em: $<$ http://www.planalto.gov.br/ccivil_03/constituicao/constituicao.htm>. Acesso em: 17 ago. 2020.

Brasil. Lei no 4.024, de 20 de dezembro de 1961. Diretrizes e Bases da Educação Nacional. Disponível em: <http://www.planalto.gov.br/ccivil_03/leis/l4024.htm>. Acesso em: 17 ago. 2020.

Brasil. Lei no 5.692, de 11 de agosto de 1971. Diretrizes e Bases para o ensino de $1^{\circ}$ e e $2^{\circ}$ graus. Disponível em: <http://www.planalto.gov.br/ccivil_03/leis/15692.htm>. Acesso em: 17 ago. 2020.

Brasil. Lei no 6.938, de 31 de agosto de 1981. Dispõe sobre a Política Nacional do Meio Ambiente, seus fins e mecanismos de formulação e aplicação, e dá outras providências. Disponível em: <http://www.planalto.gov.br/ccivil_03/Leis/L6938.htm>. Acesso em: 17 ago. 2020.

Brasil. Lei no 9.394, de 20 de dezembro de 1996. Estabelece as diretrizes e bases da educação nacional. Disponível em: <http://www.planalto.gov.br/ccivil_03/leis/ 19394.htm>. Acesso em: 17 ago. 2020.

Brasil. Lei no 9.795, de 27 de abril de 1999. Dispõe sobre a Educação Ambiental, institui a Política da Educação Ambiental e dá outras providências. Disponível em: <http://www.planalto.gov.br/ccivil_03/leis/19795.htm>. Acesso em: 17 ago. 2020.

Brasil. Parâmetros Curriculares Nacionais: meio ambiente e saúde. Brasília: MEC/SEF, 1997. v. 9. 
Brasil. Resolução MEC/CNE/CP no 1, de 15 de maio de 2006. Institui Diretrizes Curriculares Nacionais para o Curso de Graduação em Pedagogia, licenciatura. Disponível em: <http://portal.mec.gov.br/cne/arquivos/pdf/rcp01_06.pdf>. Acesso em: 17 ago. 2020.

Campos, P. C. Meio Ambiente: a sustentabilidade passa pela educação. Revista em Questão, v. 12, n. 2, p. 387-419, 2006.

Carvalho, I. C. M. A questão ambiental e a emergência de um campo de ação políticopedagógica. In: Loureiro, C. F. B.; Layrargues, P. P.; Castro, R. S. (Orgs.). Sociedade e meio ambiente: a educação ambiental em debate. 3. ed. São Paulo: Cortez, 2002.

Freire, P. Pedagogia da autonomia: saberes necessários à prática educativa. São Paulo: Paz e Terra, 1996.

Freire, P. Pedagogia do oprimido. 42. ed. Rio de Janeiro. Paz e Terra, 2005.

Grispun, M. P. S. Z. (Org.). 0 papel da orientação diante das perspectivas da escola. São Paulo: Cortez, 2008.

Guattari, F. A transversalidade (1964). In: Guattari, F. Psicanálise e transversalidade: ensaios de análise institucional. Aparecida: Ideias \& Letras, 2004.

Guimarães, M. A dimensão ambiental na educação. Campinas: Papirus, 1995. (Coleção Magistério: Formação e Trabalho Pedagógico).

Guimarães, M. A formação de educadores ambientais. Campinas: Papirus, 2004.

Guimarães, M. Educação ambiental: no consenso um embate? Campinas: Papirus, 2000. (Coleção Papirus Educação).

Japiassu, H. A atitude interdisciplinar no sistema de ensino. Revista Tempo Brasileiro, v. 108, p. 83-94, 1992.

Layrargues, P. P. Muito além da natureza: educação ambiental e reprodução social. In: Castro, R. S.; Layrargues, P. P.; Loureiro, C. F. B. (Orgs.). Pensamento complexo, dialética e educação ambiental. São Paulo: Cortez, 2006.

Leff, E. Saber ambiental. Petrópolis: Vozes, 2001.

Libâneo, J. C. Pedagogia e pedagogos, para quê? São Paulo: Cortez, 1998.

Lima, G. C. Crise ambiental, educação e cidadania: os desafios da sustentabilidade emancipatória. In: Loureiro, C. F. B.; Layrargues, P. P.; Castro, R. S. (Orgs.). Educação ambiental: repensando o espaço da cidadania. 4. ed. São Paulo: Cortez, 2008.

Lima, G. C. O Discurso da sustentabilidade e suas implicações para a educação. Revista Ambiente \& Sociedade, v. 6, n. 2, p. 99-119, 2003. https://doi.org/10.1590/S1414753X2003000300007

Maturana, H. Emoções e linguagem na educação e na política. Belo Horizonte: Editora UFMG, 1998.

Morin, E. Introdução ao pensamento complexo. Lisboa: Instituto Piaget, 2001.

Pedrini, A. G. Educação Ambiental: reflexões e práticas contemporâneas. Petrópolis: Editora Vozes, 2006.

Pequeno, M. G. C. Educação ambiental e a questão da transversalidade. João Pessoa: UFPB/UEPB, 2001. (Dissertação de mestrado). 
Perrenoud, P. A prática reflexiva no ofício de professor: profissionalização e razão pedagógica. Porto Alegre: Artmed, 2002.

Piaget, J. L'épistémologie des relations interdisciplinaires. Actas L'Interdisciplinarité Problèmes d'Enseignement et de Recherche dans les Universités, 1970.

Rosa, L. G. A dimensão ambiental no currículo da Escola Estadual Normal Pe. Emídio Viana Correia. João Pessoa: UFPB/UEPB, 2003. (Dissertação de mestrado).

Santos, B. S. A universidade no século XXI: para uma reforma democrática e emancipatória da Universidade. São Paulo: Cortez, 2005.

Sato, M.; Zakrzevski, S. B. B. Refletindo sobre a formação de professores em educação ambiental. In: Santos, J. E. S.; Sato, M. A contribuição da educação ambiental à esperança de Pandora. São Carlos: RiMa, 2001.

Silva, M. M. P. Estratégias em educação ambiental. Campina Grande: UFPB/UEPB, 2000. (Dissertação de estrado).

Silva, T. T. Os novos mapas culturais e o lugar do currículo numa paisagem pós moderna. In: Silva, T. T.; Moreira, A. F. B. Territórios contestados. Petrópolis: Vozes, 2005.

Silveira, C. 0 processo de construção de projetos de educação ambiental: as dimensões do planejamento e da avaliação. São Paulo: EDUSP, Signus, 1997.

Sorrentino, M. Educação ambiental e universidade: um estudo de caso. In: Pádua, S. M.; Tabanez, M. F. (Orgs.). Educação ambiental: caminhos trilhados no Brasil. São Paulo: IPÊ, 1997.

Stone, M. K.; Barlow, Z. Alfabetização ecológica: a educação das crianças para um mundo sustentável. São Paulo: Cultrix, 2006.

(CC) Informação da Licença: Este é um artigo Open Access distribuído sob os termos da Licença Creative Commons Attribution, que permite uso irrestrito, distribuição e reprodução em qualquer meio, desde que a obra original seja devidamente citada. 